\title{
Entrepreneurial Orientation (EO) Among Small and Medium Enterprises (SMEs) in Côte d'Ivoire
}

\author{
Aka Lucien Koffi ${ }^{1} \quad$ Li Hongbo $^{1} \quad$ Samar Zaineldeen $^{1} \quad$ Ettien Fulgence Brou ${ }^{2}$ \\ 1.School of Management, Jiangsu University 301, Xuefu Road, Zhenjiang, Jiangsu 212 013, China \\ 2.School of Finance, Jiangsu University 301, Xuefu Road, Zhenjiang, Jiangsu 212 013, China
}

\begin{abstract}
Small and Medium-sized Enterprises (SMEs) are regarded as the engine of economic growth in all economies of the world including developed and developing countries. This study explores the entrepreneurial orientation of SMEs in Côte d'Ivoire. Data for the study was obtained using survey questionnaire obtained from 150 SMEs in various sectors in Côte d'Ivoire. The data was anaylsed using structural equation model (SEM) with the help of SmartPls vs 3.2.7 for PC. Findings from the study indicate that proactiveness and risk taking influence entrepreneurial orientation positively. Additionally, findings from this study revealed a strong and positive relationship between entrepreneurial orientation and SME performance. Based on the research findings, the research concluded that SMEs in Côte d'Ivoire are entrepreneurial but lack innovation. The study recommended that SME firms in Côte d'Ivoire should pay attention to the innovativeness dimension of entrepreneurial orientation as a way of differentiation strategy to achieve sustained competitive advantage as well as profitability and growth. This paper adds to the literature on entrepreneurial orientation and firm performance among small and medium enterprises from a developing country perspective.
\end{abstract}

Keywords: Entrepreneurial Orientation, SME, firme Performance, Côte d'Ivoire

DOI: $10.7176 / \mathrm{EJBM} / 11-33-10$

Publication date: November $30^{\text {th }} 2019$

\section{Introduction}

For several decades, many have held the notion that sustainable economic development of countries depended solely on Large Enterprises (LE). This idea was predominantly based on the premise that Small and Medium-sized Enterprises (SMEs) belonged only to the informal sector. SMEs have become the number one contributor to economic development and job creation of economies (Report, 2016). Accordingly, SMEs are regarded as the engine for growth of economies of the world; not only in the developing or the least developed countries (Hamilton \& Dana, 2003; Woldie \& Adebimpe, 2004) of the world, but also in developed economies. It accounts for $85 \%$ new job creation in the United States.

In virtually every jurisdiction, from the largest economies to the smallest, over $99 \%$ of companies have fewer than 50 employees (Pacter, 2009). The United Nations Industrial Development Organisation (UNIDO) identified fifty definitions of small scale business in seventy-five different countries based on parameters such as installed capacity utilization, output, employment, capital, type of country or other criteria, which have more relevance to the industrial policies of the specific country (Beck, Thorsten, Demirguc-Kunt, Asli, \& Levine, 2006).

According to the Hong Kong Institute of Certified Public Accountants an entity is considered to be an SME in Hong Kong if it does not exceed any two of the three criteria pegged as total annual revenue of HK\$50 million, total assets of HK $\$ 50$ million, at the reporting date, and 50 employees (SME-FRF \& SME-FRS, 2005). Sian and Roberts (2006) went further to differentiate a micro entity from an SME. They defined micro-entities as the smallest entities within the SME spectrum and that these entities have less than 10 employees.

In spite of its definitional problem, there exists a high level of consensus on the importance of SMES, especially the SMEs sub-sector to economic growth and development. Oluba (2009) has, however, observed that the importance of SMEs varies with sectors and with the developmental stage of a country. He opined that developing characteristics such as the level of capital allocation management size and arrangement as well as limited market access which make SMEs less amenable to the disappointing results of development strategies that focus on large, capital intensive and high import dependent industrial plants as well as failed public enterprises

Abo (2013) finds that in Côte d'Ivoire, the SMEs sector is one of the most important drivers of economic growth and the eradication of poverty. According to the National Development Plan (PND, 2011) SMEs represented $98 \%$ of national enterprises and contributed about $18 \%$ of total GDP and offered nearly $20 \%$ of modern employment. However, this sector receives little support from the government (Abo, 2013). The economy of Cote d'Ivoire is stable and currently growing, in the aftermath of political instability in recent decades. The country is largely market-based and depends heavily on the agricultural sector. Almost $70 \%$ of the Ivorian people are engaged in some form of agricultural activity. (ESP 2018; Hongbo, 2018)

Before the independence of Côte d'Ivoire in the 1980s, the economic development of the country was tied to agriculture and the major industries operating in this sector. SMEs were little known and promoted. Most SMEs were associated with crafts, family activities, mostly in the informal sector. However, beyond the post economic 
crisis of Côte d'Ivoire in 1980s, have witnessed much attention given to SMEs. SMEs are recognized as an economic factor and provider of employment (Billon, 2013).

After a decade of crisis, Côte d'Ivoire has the ambition to make the private sector the main engine of growth and social redistribution. From 2012 to 2015, the Government of Côte d'Ivoire also launched a series of reforms to improve the business climate and encourage investment. According to the evaluation report of the PND 2012 2015, the business climate has strengthened significantly with the implementation of new codes - Investments, Mines and Electricity in particular. These institutional reforms have led to a more attractive business environment that is respectful of international standards, with the operationalization of the single window of investments, access to land ownership, the reduction of delays and the simplification of business creation formalities (ESP 2018).

Even though there has been a preponderance of studies on SMEs in Africa, however, research focusing on entrepreneurial orientation of SMEs in Africa especially in sub Saharan Africa is scarce. Also, research on SMEs in Côte d'Ivoire has been very limited and this provides an opportunity to address this study gap in literature in SME study in Côte d'Ivoire. The purpose of this study is therefore to examine the effect entrepreneurial orientation on SMEs growth in Côte d'Ivoire. The following objectives shall be pursued to:

- Explore to what an extent are SMEs in Côte d'Ivoire entrepreneurial.

- Establish the relationship between entrepreneurial orientation and SMEs firm performance

The rest of this paper is set out as follows: the next section reviews extant literature on Entrepreneurial Orientation (EO) focusing on the three dimensions of EO i.e. innovativeness, risk taking and proactiveness. The third section presents the study's methodology; whilst the fourth section presents the results of the study and discussion. Finally, the paper closes with the conclusion and some recommendations.

\section{Entrepreneurial Orientation}

Entrepreneurial Orientation (EO) refers to a firm's strategic orientation, capturing specific entrepreneurial aspects of decision-making styles, methods, and practices. As such, it reflects how a firm operates rather than what it does (Lumpkin \& Dess, 1996). Miller (1983) summarizes the characteristics of an entrepreneurial firm: "An entrepreneurial firm is one that engages in product market innovation, undertakes somewhat risky ventures, and is first to come up with "proactive" innovations, beating competitors to the punch" (p. 771). Based on this, several researchers have agreed that EO is a combination of the three dimensions: innovativeness, proactiveness, and risk taking. Thus, EO involves a willingness to innovate to rejuvenate market offerings, take risks to try out new and uncertain products, services, and markets, and be more proactive than competitors toward new marketplace opportunities (J. G. Covin \& Slevin, 1991; Wiklund, 1999; S. Zahra, 1993; S. Zahra \& Covin, 1995). These three dimensions of EO therefore form the basis of the conceptual framework developed for this study. The innovativeness dimension of EO reflects a tendency to engage in and support new ideas, novelty, experimentation, and creative processes, thereby departing from established practices and technologies (Lumpkin \& Dess, 1996). A high rate of technological and/or product market innovation, as implied by the innovativeness dimension, can be used by the firm to pursue new opportunities. Innovativeness is fundamental to contemporary definitions of entrepreneurship (Miller, 1983; Shane \& Venkataraman, 2000). Kropp, Lindsay, and Shoham (2006) identified that the innovativeness component of an entrepreneurial orientation is important to the success of a new business. Entrepreneurial firms operate in dynamic environments "where customers' tastes, product-service technologies, and competitive weapons often change unpredictability" (Miller, 1983) p.775. Innovativeness is required for product/market development in the services industry to deal with the continuous change and uncertainty. The greater the environmental dynamism and hostility, the greater the innovation required (Miller, 1983). Creative and innovative firms will outperform other firm types in more dynamic environments. Innovativeness is thus associated more with the ongoing process of business continuity once the business is started than with new entry.

According to Lumpkin and Dess (1996) proactiveness refers to a posture of anticipating and acting on future wants and needs in the marketplace, thereby creating a first-mover advantage vis-a-vis competitors. It involves pioneering behaviour undertaken to face future contingencies and overcome competitors' actions. Lumpkin and Dess (2001) conceptualize proactiveness as a mindset that focuses on introducing new products or services in anticipation of future demand and shaping the environment. Some of the activities associated with proactiveness include new opportunity identification and evaluation, identification and monitoring of market trends, and new venture team formation. Opportunity recognition is one of the key elements of the entrepreneurial process (Schwartz, Teach, \& Birch, 2005).

Lumpkin and Dess (1996) also suggested two additional narrowly related components for proactiveness; autonomy, or the independence to bring forth and implement new ideas and ventures, and competitive aggressiveness, or a challenging attitude towards competitors that attempt to achieve entry or improve their position Comparatively, entrepreneurial firms tend to develop creative and innovative projects in anticipation of the opportunities in the environment and to beat competitors' actions, and their expectations of reward involve significant but calculated risks. In contrast, non-entrepreneurial firms tend to adopt a reactive, risk-averse posture based on a policy of following and imitating competitors. In the words of Barringer and Bluedorn (1999), firms 
without entrepreneurial orientation adopt a "wait and see" posture.

According to Miller and Friesen (1982), risk taking is associated with a willingness to commit more resources to projects where the cost of failure may be high. Lumpkin and Dess (2001) also described risk taking as a component of entrepreneurial orientation and a distinctive facet of entrepreneurial behavior (Das \& Teng, 1997; S. M. Lee \& Peterson, 2000). Risk taking can be at an individual level (Brockhaus, 1980; Sitkin \& Pablo, 1992) or a firm-level trait (I.S. Baird \& H. Thomas, 1985) that differs by a firm's stage of development. Palmer and Wiseman (1999) distinguished between managerial risk, which relates to choices associated with uncertain outcomes, and organizational risks, which involves volatile income streams. Forlani and Mullins (2000) describe entrepreneurs' perception of risk as the "uncertainty and potential losses associated with the outcomes which may follow from a given set of behaviors." Defined as substantial variance in important outcomes (MacCrimmon \& Wehrung, 1986), risk represents the likelihood that an individual will forego a safe alternative with a known outcome in favor of a more attractive choice with a more uncertain reward (Brockhaus, 1980). Some aspects of strategic risk include venturing into new and unknown territories. It also involves committing a relatively large share of assets and significant borrowing (I.S Baird \& H. Thomas, 1985) pp. 231-2 cited in Lumpkin and Dess 1996).

\section{Conceptual model and Hypothesis}

The conceptual framework for the study consists of two building blocks (see figure 1). These are entrepreneurial orientation (EO) and firm performance. These are discussed next:

\section{EO Dimensions}

An entrepreneurial orientation (EO) has three key dimensions. These are innovativeness, proactiveness, and risk taking. Innovativeness is the ability of the entrepreneur to introduce innovativeness in his/her business. That is, the willingness to try the ways which are different from the existing, the enthusiasm to adopt new ideas or new methods to their business operation, and the eagerness to implement the innovation strategy in their business (Begonja, Čićek, Balboni, \& Gerbin, 2016). We propose the first hypothesis (H1) as follows:

H1: innovativeness dimension positively influences entrepreneurial orientation.

Proactiveness also refers to a posture of anticipating and acting on future wants and needs in the marketplace, thereby creating a first-mover advantage (Leischniga \& Geigenmüll, 2018). It involves pioneering behaviour undertaken to face future contingencies and overcome competitors' actions. Lumpkin and Dess (2001) conceptualize proactiveness as a mindset that focuses on introducing new products or services in anticipation of future demand and shaping the environment. We propose hypothesis 2 (H2) as follows: H2: proactiveness dimension influences entrepreneurial orientation positively.

Risk taking on the other hand, is associated with a willingness to commit more resources to projects where the cost of failure may be high (Angeloni, Faia, \& Duca, 2015). Risk taking can be at an individual level (Brockhaus, 1980; Sitkin \& Pablo, 1992) or a firm-level trait (I.S. Baird \& H. Thomas, 1985) that differs by a firm's stage of development. We therefore propose hypothesis 3 (H3) as follows: H3: There is a positive relationship between risk-taking and entrepreneurial orientation

\section{- $\quad$ Relationship between entrepreneurial orientation (EO) and firm performance}

The second construct firms' performance suggest that entrepreneurial orientation leads firms into being successful in the market place through growth in market share, profit and sales revenue (T. Lee \& Chu, 2017). Empirical findings show a positive relationship between entrepreneurial orientation and firm performance and sales growth (Zahra, 1991; S. Zahra \& Covin, 1995). J. Covin and Slevin (1989) reported a positive relationship between entrepreneurial posture and firm performance. Additional empirical results provided evidence of a strong relationship between entrepreneurial orientation and profitability and revenue generated by the firm (Smart \& Conant, 1994; S. Zahra, 1993). We propose hypothesis 4 (H4) as follows:

H4: There is a positive relationship between entrepreneurial orientation and firm performance.

-

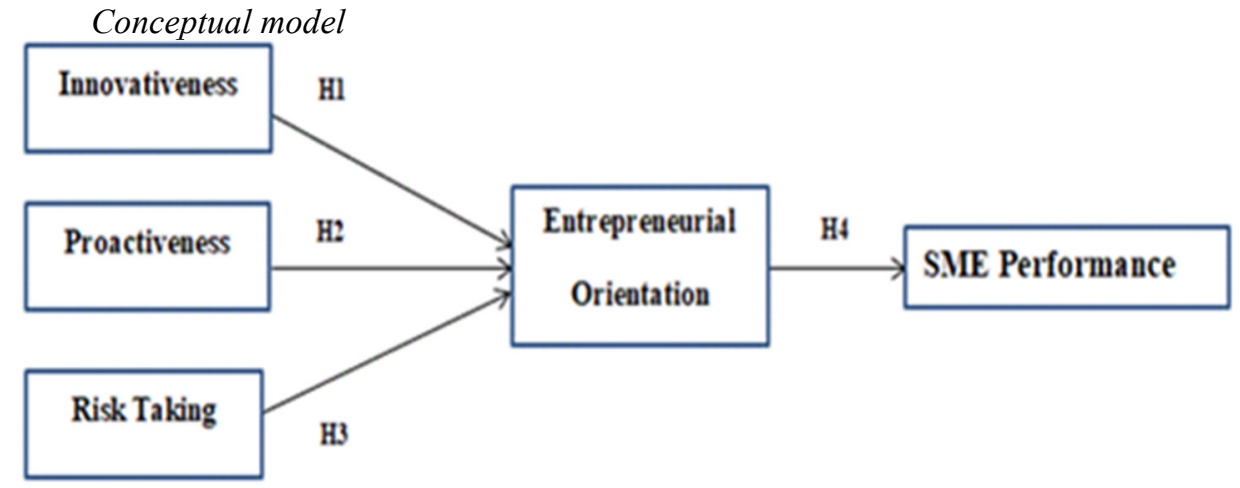

Figure 1. Conceptual model and hypothesis 


\section{Methodology}

This study employed the survey research design for the purpose of accurately assessing the impact of EO on SMEs performance. This method of research design is good for one time data collection and also helps to get current information on the issue being studied. The population consisted of SMEs in Cote d'Ivoire. A simple random sample of 250 respondents was selected for the study. A survey was conducted in the two major cities in Côte d'Ivoire (i.e. Abidjan and Korhogo) in August, 2018. Out of the 250 questionnaire administered, a 150 usable questionnaire were obtained, representing $66.67 \%$ response rate.

The researcher employed quota sampling and simple random sampling methods for selecting respondent. The first stage was the stratification of the respondents based on their sector of operation to determine the number of managers for each category. Simple random sampling was then used to select appropriate quota based on the following categories, namely Agriculture, Manufacturing and Service. The simple random sampling assigns equal probability to each element in the target population and respondents were selected through shop to shop visitation (see Table 1)

Table 1. Quota Assigned to Sectors of SMEs

\begin{tabular}{ll}
\hline Business Sectors & Number of respondents \\
\hline Agriculture & 65 \\
Manufacturing & 45 \\
Service & 40 \\
Total & $\mathbf{1 5 0}$ \\
\hline
\end{tabular}

A self-administered, structured questionnaire was developed, pre-tested and finally administered to the respondents through personal contact by researchers within four weeks. The researchers used informed consent form to seek permission from the respondents and assured the respondents of anonymity and confidentiality of their responses. A five point Likert scale was used to measure variables for the research constructs as recommended in previous work (Danaher \& Haddrell, 1996). The Likert scale ranged from strongly disagree to strongly agree, coded 1 to 5 respectively. In all, the measurement items for the five multi-item constructs had 19 items that were derived from previous studies and modified to suit the research context. The questionnaire also contained respondents' demographic data: age of business, education level of owner/managers and ownership structure. The data was anaylsed using structural equation model (SEM) with the help of SmartPls vs 3.2.7 for PC.

\section{Results}

- Reliability and validity

Data were first analyzed to ensure instrument quality by convergent and discriminant validity. Applying SPSS, the exploratory factor analysis (EFA) was conducted to measure the underlying dimension associated with 12 items. The constructs validity was measured using Bartlett's test of Sphericity and Kaiser-Mayer-Olkin (KMO) measure of the sampling adequacy of individual variables. KMO overall should be 0.6 or over to perform factor analysis (Özdamar, 2013). According to the results of Bartlett's test of Sphericity and KMO revealed that both are significant and suitable for the factor analysis (.870, see Table 2$)$. The cumulative variance explained is $93 \%$ which exceeds the acceptable limit of $60 \%$ (Özdamar, 2013). The value of Bartlett's test of Sphericity indicate sufficient correlation between the variables, it shows 1026.387 and significant $(\mathrm{p}>0.000)$. The factor loading of all items of each scale exceeds 0.5 (Hair, Ringle, \& Sarstedt, 2011). Thus these values constitute of evidence of convergent validity.

Table 2. Quota Assigned to Sectors of SMEs

Kaiser-Meyer-Olkin Measure of Sampling Adequacy.

Bartlett's Test of Sphericity Approx. Chi-Square

Df

1026.387

Sig.

- Measurement model reliability and validity

Construct reliability measures the extent of internal consistency of measures used, and it is assessed through at item factor loadings with acceptable value of 0.70 and through Cronbach's alpha with the acceptable level of 0.7 (Hair et al., 2011; Ringle, Henseler, \& Sarstedt, 2015). From Table 3, all of the constructs have item loadings higher than the recommended 0.70 . 
Table 3. Item loading, construct reliability and discriminant validity

\begin{tabular}{llllll}
\hline & FL & VIF & CA & CR & AVE \\
\hline inno1 & 0.792 & 1.402 & 0.495 & 0.723 & 0.509 \\
inno2 & 0.259 & & & & \\
inno3 & 0.913 & & & 0.902 & 0.754 \\
pro 1 & 0.865 & 1.748 & 0.838 & & \\
pro 2 & 0.885 & & & 0.852 & 0.657 \\
pro 3 & 0.855 & & 0.747 & & \\
risk 1 & 0.749 & 1.846 & & 0.848 & \\
risk 2 & 0.816 & & & & \\
risk 3 & 0.843 & & 0.736 & & \\
eo1 & 0.748 & 1.418 & & 0.846 & \\
eo2 & 0.806 & & & & \\
eo3 & 0.864 & & 0.747 & & \\
perf 1 & 0.698 & 1.441 & & & \\
perf 2 & 0.829 & & & & \\
perf 3 & 0.881 & & & & \\
\hline
\end{tabular}

Notes: FL - Item Loadings, INNO - Innovativeness, PRO- Proactiveness, RISK- Risk Taking, PERF Performance, EO-Entrepreneurial Orientation, AVE-Average variance extracted, CR-Composite reliability, $C A$ - Cronbach's alpha

Moreover, in Table 3, all the variables returned Cronbach's alphas above 0.70 (except innovativeness), indicating that these multiple measures are highly reliable for the measurement of each construct. Construct validity assesses the degree to which a measurement represents and logically connects the observed phenomenon to the construct through the fundamental theory (Fornell \& Larcker, 1981). It is assessed through convergent validity and discriminant validity (Ringle et al., 2015). Convergent validity was considered adequate since the average variance extracted (AVEs) and composite reliability (CR) satisfied the minimum of 0.50 and 0.70 respectively (Fornell \& Larcker, 1981; Ringle et al., 2015).

- $\quad$ Assumed model and hypotheses

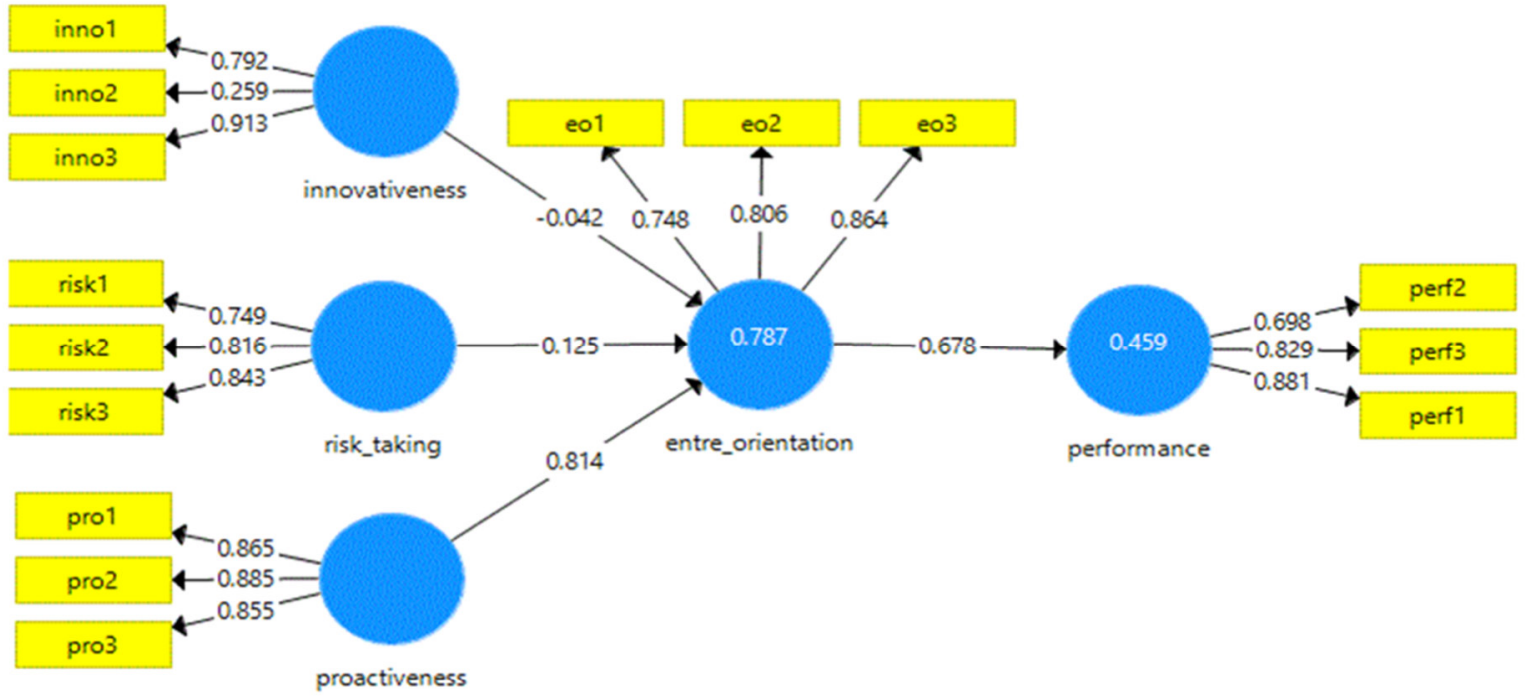

- Results of Structural Model

The structural model was assessed through the regression weights, t-values, p-values for significance of t-statistics (Chin \& Dibbern, 2010; Ringle et al., 2015). The results of structural model for testing the research hypotheses are presented in Table 4. 
Table 4. Item loading, construct reliability and discriminant validity

\begin{tabular}{llllll} 
Hypothesis & Relationship & Estimate & SE & T-Stat & p-value \\
\hline H1 & Inno - Perf & -1.036 & -0.108 & -1.561 & 0.121 \\
H2 & Pro - Perf & 0.627 & 0.736 & 6.606 & $* * *$ \\
H3 & Risk--- Perf & 0.224 & 0.224 & 2.499 & 0.014 \\
& R-Square (Perf) & 0.579 & & & \\
Model 2 & Adj. R (Perf) & 0.570 & & & \\
H4 & & & & & $* *$ \\
& EO - Perf & 0.678 & 0.613 & 9.431 & $*$ \\
& R-Square (Perf) & 0.787 & & & \\
\hline
\end{tabular}

Note: ** significant at 0.05, *** significant at 0.001; INNO - Innovativeness, PRO-Proactiveness, RISK-Risk Taking, PERF - Performance; EO - Entrepreneurial Orientation

The results in Table 3 show that, all the hypotheses proposed were supported except one (H1). Hypotheses 2 and 3 were supported; however, hypothesis 1 was not supported. First of all, the direct effect proactiveness and risk taking on SME performance were supported $(\mathrm{H} 2, \mathrm{H} 3 ; \mathrm{p}<0.05)$. However, hypothesis $\mathrm{H} 1$ was not supported $(\mathrm{p}>0.05)$. The results shows that proactiveness dimension influences EO more than the other two dimensions ( $\beta$ $=0.627 ; \mathrm{t}=8.39 ; \rho=0.000)$. Also, risk taking dimension influences EO significantly $(\beta=0.224 ; \mathrm{t}=2.39 ; \rho=$ $0.018)$. The R-square score $(57.9 \%)$ shows that, overall, the independent variables proactiveness and risk taking influence entrepreneurial orientation about $58 \%$. This means that, together, the independent variables contribute significantly to EO by about $58 \%$.

The second model also shows that hypothesis 4 is significant; that is, entrepreneurial orientation influences performance positively $(\beta=0.613 ; t=9.431 ; \rho=0.000)$. The R-square score for the second model $(0.7879 \%)$ shows that, entrepreneurial orientation influences SME performance by about $79 \%$.

\section{Discussion}

The main of this study was to assess the effect of entrepreneurial orientation on SMEs performance. First and foremost this study revealed that EO dimensions that influence the overall EO are proactiveness, risk taking and innovativeness. Proactiveness contributes more to EO than any other dimension (81.4\%). This is followed by risk taking $(12.5 \%)$ and innovativeness $(-4.2)$. this finding suggests that, when it comes to the dimensions that influences SMEs to be entrepreneurial, proactiveness contributes more followed by risk taking. However, innovativeness in this study is seen to contribute insignificantly to SMEs entrepreneurial activities in Côte d'Ivoire. This means that SMEs in Côte d'Ivoire are not innovative but are risk takers and also look out for new opportunities. With regards to the hypothesis tested in this study, three out of the four research hypotheses tested were accepted. The first hypothesis which states that innovativeness dimension of EO would influence SME performance was not accepted. This means that SMEs innovativeness does not influence performance of SMEs in Côte d'Ivoire. This finding however contradicts earlier findings that suggest that innovativeness has a strong positive correlation with performance (Begonja et al., 2016; Lumpkin \& Dess, 1996, 2001)

The second hypothesis was also accepted. This means that the proactiveness dimension of EO has a positive and significant relationship with SMEs performance. What this means is that SMEs in Côte d'Ivoire are able to look for new growth opportunities to achieve a sustained positive performance. This agrees with what Leischniga \& Geigenmüll (2018) mentioned that proactiveness is the ability to anticipate and act on future wants and needs in the marketplace, thereby creating a first-mover advantage (Leischniga \& Geigenmüll, 2018).

Additionally, this study found a positive and significant relationship between risk taking propensity of SMEs and performance. Risk taking involves a willingness to commit more resources to projects where the cost of failure may be high. However, the more SMEs are able and ready to take risk, the more successful they are in achieving targeted growth. This finding also supports earlier findings that suggest that SMEs risk taking has a positive and significant effect on SMEs performance (Angeloni et al, 2015).

\section{Conclusion}

The current research investigates the entrepreneurial orientation of SMEs in Côte d'Ivoire within the same category. That is, it investigated how SMEs in Côte d'Ivoire are entrepreneurial by being innovative, risk taking and proactive which are internal factors that motivate or influence entrepreneurial success. We can also firmly conclude that an entrepreneurial firm is the one that is innovative, risk taking and proactive. Finally, we can also conclude that there is a strong correlation between EO and firm performance which includes growth and competitive advantage. 
- $\quad$ Managerial Implications

The results from this study show that SMEs in Côte d'Ivoire are risk takers as well as opportunity seekers who make use of their scarce resources and capabilities effectively and efficiently in achieving competitive advantage. However, with regards to the innovativeness aspect, it appears SMEs in Côte d'Ivoire are lacking in that aspect. In order to have a sustained competitive advantage however, SMEs need to generate new ideas and implement same in their daily business activities in order to achieve the desired results of growth and profitability.

The results of the study should also be very significant to management as reward for hard work. Management from all indications has invested and will continue to invest heavily in their operations to stay competitive and achieve the desired outcome of growth and profitability.

\section{- Recommendations}

Based on the findings made in the preceding section, the following recommendations are proffered. First and foremost, the study recommends that SME firms in Côte d'Ivoire should pay attention to the innovativeness dimension of entrepreneurial orientation as a way of differentiation strategy to achieve sustained competitive advantage as well as profitability and growth. Second, SMEs must invest in technological innovations to enable them grow and develop their businesses to be able to compete effectively domestically and in the international marketing space. Finally, SMEs in Côte d'Ivoire must endeavor to develop competencies and marshal the needed resources to metamorphose into bigger businesses in the future.

\section{References}

Abo. (2013). An Empirical Investigation of Ivorian SMEs Access to Bank Finance: Constraining Factors at Demand-Level. Journal of Finance and Investment Analysis, 2(4), 29-55.

Angeloni, Faia, \& Duca. (2015). Monetary policy and risk taking Journal of Economic Dynamics and Control 52, 285-307.

Baird, I.S., \& Thomas, H. . (1985). Toward a contingency model of strategic risk taking. Academy of Management Review, 10(2), 230-243.

Barringer, \& Bluedorn. (1999). The Relationship Between Corporate Entrepreneurship and Strategic Management. Strategic Management Journal 20(5). doi: 10.1002/(SICI)1097 0266(199905)20:5<421::AID$\mathrm{SMJ} 30>3.0 . \mathrm{CO} ; 2-\mathrm{O}$

Beck, Thorsten, Demirguc-Kunt, Asli, \& Levine, R. (2006). A New Database on Financial Development and Structure World Bank Policy Resarch Working Paper No. WPS 2146, 1960-2004.

Begonja, Čićek, Balboni, \& Gerbin. (2016). Innovation and business performance determinants of SMEs in the Adriatic region that introduced social innovation. Economic Research-Ekonomska Istraživanja, 29(1), 11361149.

Billon, J. (2013). Rôle des PME dans l'économie ivoirienne. Paper presented at the Déjeuner-Débat H E C, Republique de Cote d'Ivoire.

Brockhaus, R.H. . (1980). Risk taking propensity of entrepreneurs. Academy of Management Journal, 23(3), 509520.

Chin, W.W., \& Dibbern, J. (2010). Handbook of Partial Least Squares: Concepts, Methods and Applications.

Covin, J.G. , \& Slevin, D.P. . (1991). A conceptual model of entrepreneurship as firm behavior. Entrepreneurship Theory \& Practice, 16(1), 7-25.

Covin, JG., \& Slevin, P. (1989). Strategic management of small firms in hostile and benign environments. Strategic Management Journal, 10(1), 75-87.

Danaher, \& Haddrell. (1996). A comparison of question scales used for measuring customer satisfaction. International Journal of Service Industry Management, 7(4), 4-26.

Das, T. K., \& Teng, B. K. . (1997). Time and entrepreneurial risk behavior. Entrepreneurship Theory and Practice, 22(2), 69-88.

ESP , Entrepreneurial Solutions Patners \& ADB, African Development Bank (2018). Étude sur le secteur privé et le financement des TPE/PME en Côte d'Ivoire.

Forlani, D. , \& Mullins, J. W. . (2000). Perceived risks and choices in entrepreneurs' new venture decisions. Journal of Business Venturing, 15(4), 305-322.

Fornell, C., \& Larcker, D.F. (1981). Evaluating Structural Equation Models with Unobservable Variables and Measurement Error. Journal of Marketing Research, 8(1), 39-50. doi: 10.2307/3151312

Hair, J., Ringle, C., \& Sarstedt, M. (2011). PLS-SEM: Indeed a Silver Bullet. Journal of Marketing Theory and Practice, 19(2), 139-152.

Hamilton, R.T. , \& Dana, L. (2003). An increasing role for small business in New Zealand. Journal of Small Business Management, 41(4), 402-408.

Hongbo, L., Lucien, K. A., Raphael, Y. K., \& Boris, A. A. (2018). Contribution of Small Medium Enterprises (SMEs) to Economic Development: Comparative Study of China and Cote d'lvoire. International Journal of Academic Research in Business \& Social Sciences, 8(11), 1896-1915. 
Kropp, F., Lindsay, N. a, \& Shoham, A. (2006). Entrepreneurial, market, and learning orientations and international entrepreneurial business venture (IEBV) performance in South

Lee, S. M. , \& Peterson, S.J. . (2000). Culture, entrepreneurial orientation, and global competitiveness. Journal of World Business, 35(4), 401-416.

Lee, T., \& Chu, W. (2017). The relationship between entrepreneurial orientation and firm performance: Influence of family governance. Journal of Family Business Strategy, 8(4), 213-223.

Leischniga, \& Geigenmüll. (2018). When does alliance proactiveness matter to market performance? A comparative case analysis. Industrial Marketing Management, 74, 79-88.

Lumpkin, \& Dess. (1996). Clarifying the entrepreneurial orientation construct and linking it to performance. Academy of Management Review, 21(1), 135-172.

Lumpkin, \& Dess. (2001). Linking two dimensions of entrepreneurial orientation to firm performance: the moderating role of environment and industry life cycle. Journal of Business Venturing, 17, 429-451.

MacCrimmon, \& Wehrung. (1986). Recent Developments in the Foundations of Utility and Risk Theory (Vol. 47): Springer, Dordrecht.

Miller. (1983). The correlates of entrepreneurship in three types of firms. Management Science, 29(7), 770-791.

Miller, \& Friesen. (1982). Innovation in conservative and entrepreneurial firms: Two models of strategic momentum. Strategic Management Journal, 3, 1-25.

Özdamar, K. (2013). Paket Programlar ile İstatistiksel Veri Analizi-II. Eskişehir: Nisan Kitabevi.

Palmer, T. B. , \& Wiseman, R. M. . (1999). Decoupling risk taking from income stream uncertainty: a holistic model of risk. Strategic Management Journal, 10(11), 1037-1062.

Report, W. T. O. (2016). Levelling the trading field for SME: World Trade Organasation.

Ringle, CM., Henseler, J., \& Sarstedt, M. (2015). A new criterion for assessing discriminant validity in variancebased structural equation modeling. Journal of the Academy of Marketing Science, 43 (1), 115-135.

Schwartz, R. G., Teach, R. D. , \& Birch, N. J. . (2005). A longitudinal study of entrepreneurial firm opportunity recognition and product management strategies: implications by firm type. International Journal of Entrepreneurial Behaviour and Research, 11(4), 315-329.

Shane, S. , \& Venkataraman, S. . (2000). The promise of entrepreneurship as a field of research. The Academy of Management Review, 25(1), 217-226.

Sian, S., \& Roberts, C. (2006). Micro-entity financial reporting: Perspectives of preparers and users. IFAC Consultation Paper.

Sitkin, S. B. , \& Pablo, A. L. . (1992). Reconceptualizing the determinants of risk behavior. Academy of Management Review, 17(1), 9-38.

SME-FRF, \& SME-FRS. (2005). Small and Medium-sized Entity Financial Reporting Framework and Financial Reporting Standard. Hong Kong Institute of Certified Public Accountants

Smart, D. T. , \& Conant, J. S. . (1994). Entrepreneurial orientation, distinctive marketing competencies and organizational performance. ournal of Applied Business Research, 10(3), 28-38.

Wiklund, J. (1999). The Sustainability of the Entrepreneurial Orientation Performance Relationship. Entrepreneurship Theory and Practice, 24(1), 37-48.

Woldie, A., \& Adebimpe, A. (2004). Female entrepreneurs in a transitional economy: Business women in Nigeria. International Journal of Social Economics, 31(2), 78-79.

Zahra. (1991). Predictors and financial outcomes of corporate entrepreneurship: An exploratory study. Journal of Business Venturing, 6(4), 259-285.

Zahra, S. (1993). A conceptual model of entrepreneurship as firm behaviour: A critique and extension. Entrepreneurship Theory and Behavior, 17(4), 5-21.

Zahra, S., \& Covin, J. (1995). Contextual influences on the corporate entrepreneurship-performance relationship: a longitudinal analysis. Journal of Business Venturing, 10(1), 43-58. 